\title{
Estudo preliminar toxicológico, antibacteriano e fitoquímico do extrato etanólico das folhas de Jatropha mollissima (Pohl) Baill. (pinhão-bravo, Euphorbiaceae), coletada no Município de Tauá, Ceará, Nordeste Brasileiro
}

\author{
BRAQUEHAIS, I.D.'; VASCONCELOS, F.R.'; RIBEIRO, A.R.C. '; DA SILVA, A.R.A'; FRANCA, M.G.A.2; DE \\ LIMA, D.R.2; DE PAIVA, C.F.'; GUEDES, M.I.F.; MAGALHÃES, F.E.A. ${ }^{12^{*}}$ \\ -Universidade Estadual do Ceará, Laboratório de Bioquímica Humana, Centro de Ciências da Saúde, CEP \\ 60740-000, Av. Dr. Silas Munguba 1700, Fortaleza, Ceará, Brasil. Tel./Fax: +55-85-31019822. 2Universidade \\ Estadual do Ceará, Laboratório de Bioprospecção de Produtos Naturais e Biotecnologia, Centro de Educação, \\ Ciências e Tecnologia da Região dos Inhamuns, CEP 63660-000, Rua Solon Medeiros, S/N, BR 020. Bairro \\ Bezerra e Sousa, Tauá, Ceará, Brasil. *Autor para correspondência: fernanimagalhaes@yahoo.com.br
}

\begin{abstract}
RESUMO: A cada dia, cepas bacterianas estão tornando-se resistentes a diversos antibióticos, o que faz necessária a busca de novas substâncias eficazes para o tratamento de doenças. Desta forma, este trabalho reporta o estudo preliminar toxicológico, antibacteriano e fitoquímico do extrato etanólico das folhas de Jatropha mollissima (pinhão-bravo, Euphorbiaceae), coletada no Município de Tauá, Ceará, Nordeste Brasileiro. Inicialmente, realizou-se o teste de toxicidade do extrato contra Artemia salina. Na sequencia, foi realizado o ensaio antibacteriano contra quatro cepas bacterianas Gram-negativas (Escherichia coli ATCC 25922, Pseudomonas aeruginosa ATCC 27853, Hafnia alvei ATCC 51873, Klebsiella pneumoniae ATCC 13883) e uma cepa Grampositiva (Enterococcus faecalis ATCC 29212). Finalmente, fez-se a análise fitoquímica preliminar do extrato ativo para detecção das principais classes de metabólitos especiais. Como resultado, o extrato etanólico das folhas de J. mollissima se mostrou tóxico para Artemia salina, pois apresentou $\mathrm{CL}_{50}$ igual a 406,02 $\mu \mathrm{g} / \mathrm{mL}$. Quanto à ação antibacteriana, o extrato se mostrou ativo contra a bactéria Gram-positiva Enterococcus faecalis ATCC 29212, apresentando moderada atividade antibacteriana (halo de inibição igual a 7,03 mm). Evidenciou-se no extrato bioativo a presença de cumarinas, fenóis, taninos, flavonoides (flavonóis e flavanonas), alcaloides e esteroides, ambas as classes reportadas como antimicrobianos. Portanto, esse extrato tem potencial para ser usado na produção de fármacos contra infecções causadas por bactérias Gram-positivas. No entanto, as informações direcionam estudos futuros para o isolamento e identificação dos compostos bioativos, monitorados sob a ação antibacteriana mais expressiva.
\end{abstract}

Palavras-chave: Extrato vegetal, Jatropha mollissima, Metabólitos secundários, Artemia salina, Atividade antibacteriana, Enterococcus faecalis.

\begin{abstract}
Toxicological, antibacterial, and phytochemical preliminary study of the ethanolic extract of Jatropha mollissima (Pohl) Baill (pinhão-bravo, Euphorbiaceae) leaves, collected in Tauá, Ceará, Northeastern Brazil. Each day, bacterial strains are becoming more resistant to various antibiotics, which requires the search for new effective substances for the treatment of diseases. Thus, this study reports the toxicological, antibacterial, and phytochemical preliminary study of the ethanolic extracts of Jatropha mollissima (pinhão-bravo, Euphorbiaceae) leaves, collected in Tauá, Ceará, Northeast of Brazil. Initially, we performed the toxicity testing of the extract against Artemia salina. Then, we conducted the antibacterial assay against four Gram-negative bacterial strains (Escherichia coli ATCC 25922, Pseudomonas aeruginosa ATCC 27853, Hafnia alvei ATCC 51873, Klebsiella pneumoniae ATCC 13883), and one Gram-positive strain (Enterococcus faecalis ATCC 29212). Finally, we carried out the preliminary phytochemical analysis of the active extract to detect the main classes of special metabolites. As a result, the ethanolic extract of $J$. mollissima leaves was toxic to Artemia salina, because it presented $\mathrm{LC}_{50}$ equal to $406.02 \mu \mathrm{g} / \mathrm{mL}$. Regarding antibacterial action, the extract was active against the Gram-positive bacteria Enterococcus faecalis ATCC 29212, with moderate antibacterial activity (inhibition zone equal to $7.03 \mathrm{~mm}$ ). The bioactive extract had the presence
\end{abstract}

Recebido para publicação em 22/08/2015

Aceito para publicação em 23/06/2016

10.1590/1983-084X/15_164

Rev. Bras. PI. Med., Campinas, v.18, n.2, supl. I, p.582-587, 2016. 
of coumarins, phenols, tannins, flavonoids (flavanols and flavonones), alkaloids and steroids, both classes reported as antimicrobials. Therefore, this extract has the potential to be used in the production of drugs against infections caused by Gram-positive bacteria. However, these information require further studies for the isolation and identification of bioactive compounds, monitored under the more expressive antibacterial action.

Keywords: Plant extract, Jatropha mollissima, Secondary metabolites, Artemia salina, Antibacterial activity, Enterococcus faecalis.

\section{INTRODUÇÃO}

Nas últimas décadas observa-se grande interesse pelo potencial terapêutico das plantas medicinais. Diversos são os estudos científicos que investigam moléculas antimicrobianas naturais presentes em plantas, com resultados muito promissores para a busca de novas substâncias bioativas. Apesar do uso de plantas para fins terapêuticos ser muito difundido, as pessoas desconhecem o fato de que elas podem apresentar toxicidade, tanto para o homem, quanto para os amimais: assim, é importante avaliar seu grau toxicológico, pois mesmo possuindo atividades medicinais, sendo tóxico, seu uso se tornará inviável (Pereira et al., 2014).

Dados na literatura reportam que a ocorrência de bactérias resistentes a antibióticos têm despertado o interesse de pesquisas para o desenvolvimento de novas substâncias antimicrobianas, pois o fenômeno da resistência bacteriana a diversos antibióticos e agentes quimioterápicos impõe sérias limitações às opções para o tratamento de infecções bacterianas, representando uma ameaça para a saúde pública. Assim, os produtos derivados de plantas vêm ganhando destaque como fonte alternativa de compostos antimicrobianos, como exemplo, extratos de plantas ricos em compostos fenólicos (De Pinho et al., 2012; De Oliveira et al., 2011), taninos, esteroides e alcaloides (Bessa et al., 2013; Mendes et al., 2011).

A espécie Jatropha mollissima (Pohl) Baill., popularmente conhecida como pinhão-bravo, pertencente à família Euphorbiaceae é endêmica da Caatinga. Diversos trabalhos tem demonstrado que esta espécie tem grande importância farmacológica, pois apresenta efeito anti-helmíntico, hipotensor e estimulante dos músculos lisos do intestino e do útero, antioxidante, bem como antibacteriano (Ribeiro et al., 2014).

Baseando-se no exposto, este trabalho reporta o estudo preliminar toxicológico, antibacteriano e fitoquímico do extrato etanólico das folhas de Jatropha mollissima (pinhão-bravo, Euphorbiaceae), coletada em Tauá, Ceará, Nordeste Brasileiro.

\section{MATERIAL E MÉTODO}

\section{Amostra vegetal}

Os procedimentos de coleta e herborização da amostra vegetal foram realizados baseando-se nas metodologias de Cartaxo et al. (2010). A planta foi coletada na microrregião dos Inhamuns (Tauá, Ceará), $\left(040^{\circ} 18^{\prime} 05,4^{\prime \prime} \mathrm{W}\right.$; 06 $\left.{ }^{\circ} 01^{\prime} 03,6^{\prime \prime} \mathrm{S}\right)$, com autorização do SISBIO, conforme comprovantes de registro para coleta de material botânico, fúngico e microbiológico de $n^{\circ}$ 29145-2. A identificação botânica foi realizada no Herbário Caririense Dárdano de Andrade-Lima da Universidade Regional do Cariri-URCA, e depositada uma exsicata de $n^{\circ}$ 6675.

\section{Bactérias}

Foram utilizadas cepas bacterianas padrões, sendo quatro Gram-negativas (Escherichia coli ATCC 25922, Pseudomonas aeruginosa ATCC 27853, Hafnia alvei ATCC 51873, Klebsiella pneumoniae ATCC 13883 e uma cepa Gram-positiva (Enterococcus faecalis ATCC 29212).

\section{Obtenção do extrato}

O extrato bruto foi obtido das folhas de Jatropha mollissima (pinhão-bravo, Euphorbiaceae), sendo empregada a metodologia descrita por Turnes et al. (2014), com adaptações. Nestas adaptações, o material vegetal foi submetido à secagem a temperatura ambiente $\left(30 \pm 2^{\circ} \mathrm{C}\right)$, e $255,2 \mathrm{~g}$ de folhas secas, foram trituradas e submersas em $700 \mathrm{~mL}$ de etanol comercial $\left(96^{\circ} \mathrm{GL}\right)$ para extração a frio por $96 \mathrm{~h}$. Em seguida, foram realizadas filtrações simples, sob condições assépticas, e após evaporação simples do solvente, em banhomaria a $50^{\circ} \mathrm{C}$ (Souza et al., 2011), 22,8 g do extrato obtido $(8,93 \%)$ foram submetidos às avaliações preliminares de toxicidade, atividade antibacteriana e fitoquímica.

Toxicidade do extrato etanólico de Jatropha mollissima sobre Artemia salina

Para analise da evolução da toxicidade do extrato etanólico das folhas de J. mollissima foi 
utilizada a metodologia descrita por Ribeiro et al. (2014). O extrato bruto foi diluído em solução de dimetilsulfóxido (DMSO) a 1\%, nas concentrações 100, 500 e $1000 \mu \mathrm{g} / \mathrm{mL}$. Utilizaram-se três grupos controle: GC1 (Grupo Controle 1: DMSO a 1\%); GC2 (Grupo Controle 2: Solução salina isotônica); GC3 (Grupo controle 3: NaClO a 1\%). Os valores obtidos com a média do número de náuplios mortos foram submetidos à análise estatística, em que a concentração letal foi estimada em $50 \%\left(\mathrm{CL}_{50}\right)$ das larvas pelo método de Análise de Probit, de acordo com o teste de Spearman-Karber com intervalos de confiança de 95\%, usando o software TRIMMED (versão 1,5).

\section{Atividade antibacteriana}

Para a avaliação da atividade antibacteriana do extrato etanólico das folhas de J. mollissima foi empregado o método de difusão em ágar para avaliar os halos de inibição $(\mathrm{HI})$ do crescimento microbiano, baseando-se em metodologia proposta por De Oliveira et al. (2011), com adaptações. Nestas adaptações, foram utilizados discos de papel, secos e estéreis, com $6 \mathrm{~mm}$ de diâmetro. Tais discos foram embebidos com $20 \mu \mathrm{L}$ de extrato solubilizado em etanol comercial $\left(96^{\circ} \mathrm{GL}\right)$, nas concentrações de 250 $\mathrm{mg} / \mathrm{mL}$ e $25 \mathrm{mg} / \mathrm{mL}$. Em seguida os discos foram mantidos em estufa de secagem a temperatura de $50^{\circ} \mathrm{C}$, por 2 horas, tempo suficiente para secagem. Secos, os discos foram depositados em placas de Petri estéreis, contendo ágar MuellerHinton, previamente semeadas, utilizando-se swabs estéreis, com os microrganismos testados padronizados na escala 0,5 de McFarland (1,5 x 108 UFC/mL). Como controle positivo foram utilizados os antibióticos comerciais Cloranfenicol (4 mg/ $\mathrm{mL}$ ) e Estreptomicina (1 $\mathrm{mg} / \mathrm{mL})$, enquanto que o etanol comercial $\left(96^{\circ} \mathrm{GL}\right)$, foi utilizado como controle negativo. Após todo o procedimento, as placas foram incubadas em estufa bacteriológica a $37^{\circ} \mathrm{C}$ por 24 horas. Em seguida, a avaliação da atividade antimicrobiana foi realizada a partir da leitura dos halos de inibição do crescimento bacteriano (HI, em milímetros), feita com a utilização de um paquímetro. Os testes foram efetuados em triplicata contra as bactérias descritas anteriormente. A atividade antibacteriana do extrato foi classificada em sem atividade antibacteriana $(\mathrm{HI}=0 \mathrm{~mm})$, com pouca atividade antibacteriana $(0 \mathrm{~mm}<\mathrm{HI}<7 \mathrm{~mm})$, com moderada atividade antibacteriana $(7 \mathrm{~mm} \leq \mathrm{HI} \leq 13$ $\mathrm{mm})$ e com elevada atividade antibacteriana $(\mathrm{HI}>$ $13 \mathrm{~mm}$ ), contra as cepas bacterianas desafiados.

\section{Análise estatística}

Os resultados da atividade antibacteriana foram expressos em halos de inibição do crescimento celular bacteriano $(\mathrm{HI})$ e analisados segundo suas médias e respectivos desvios-padrão, bem como submetidos à análise de variância (ANOVA) no programa GraphPadPrism (versão 5.0). Diferenças significativas $(p<0,05)$ entre as médias foram determinadas pelo teste de comparações múltiplas de Tukey.

\section{Triagem fitoquímica}

O extrato etanólico das folhas de J. mollissima foi submetido à análise fitoquímica preliminar baseando-se em métodos qualitativos, propostos por Sousa et al. (2015). Nestes experimentos, a caracterização das principais classes de metabólitos especiais foi realizada através de reações químicas que resultaram no desenvolvimento de coloração e/ou precipitado, após adição de reagentes específicos, característicos para as seguintes classes de metabólitos: cumarinas, fenóis, taninos, flavonóis, flavanonas, alcalóides, esteróides e triterpenóides. Nesses experimentos, foram preparadas soluções dos extratos, dissolvendo-se $1,0 \mathrm{~g}$ de cada extrato com $100 \mathrm{~mL}$ de álcool $70 \%$. Posteriormente, alíquotas de $3 \mathrm{~mL}$ de cada solução de extrato foram adicionados em tubos de ensaios para caracterização dos grupamentos. Os resultados foram também confirmados em cromatografia em camada delgada (CCD), utilizando-se os reveladores químicos característicos para cada tipo de reação. Todos os experimentos foram realizados em triplicata e as classes de compostos presentes no extrato foram classificadas em presente $(+)$ e ausente (-).

\section{RESULTADOS E DISCUSSÃO}

$\mathrm{Na}$ avaliação in vitro da evolução da toxicidade do extrato etanólico das folhas de Jatropha mollissima, coletada em Tauá-CE, frente a Artemia salina, constatou-se que o extrato foi capaz de causar mortalidade de $50 \%$ dos náuplios, pois apresentou $\mathrm{CL}_{50}$ de $406,02 \mu \mathrm{g} / \mathrm{mL}$, com desvio padrão variando entre 295,04-558,73. Esse extrato é considerado tóxico, pois segundo Meyer et al. (1982), são considerados tóxicos extratos que apresentam $\mathrm{CL}_{50}$ inferior a $1.000 \mu \mathrm{g} / \mathrm{mL}$.

O resultado apresentado é considerado importante, pois sugere que essa amostra não pode ser utilizada como fitoterápico, pois assim como assinala Simões \& de Almeida (2015), se a amostra testada se mostrou tóxica para $A$. salina, seus efeitos também serão os mesmos em humanos. Porém, segundo Bose et al. (2011), extratos vegetais tóxicos contra $A$. salina também podem apresentar potencial pesticida, antitumoral, bem como antimicrobiano.

Esse resultado corrobora com a importância do potencial farmacológico do extrato etanólico 
das folhas de J. mollissima, haja vista que em nossos trabalhos anteriores (Ribeiro et al., 2014), foi possível detectar o efeito tóxico contra Artemia salina de extrato etanólico do caule de J. mollissima, também coletada em Tauá-CE, obtendo como resultado, a $\mathrm{CL}_{50}$ igual a $660,80 \mu \mathrm{g} / \mathrm{mL}$.

Como triagem inicial de extratos vegetais, 0 teste de toxicidade sobre o microcrustáceo marinho Artemia salina tem sido bastante utilizado, por ser de baixo custo, fácil execução e não requerer maiores cuidados com assepsia (Andrade et al., 2014), sendo assim, considerado parâmetro utilizado em testes para a detecção de substâncias bioativas em extratos de plantas com efeitos antibacterianos (Sobral et al., 2009). Dessa forma, no presente estudo utilizou-se como parâmetro inicial a $\mathrm{CL}_{50}$ dos náuplios de Artemia salina, e somente após o resultado investigou-se a sua ação antimicrobiana sobre quatro cepas bacterianas Gram-negativas e uma cepa Gram-positiva.

$\mathrm{Na}$ avaliação in vitro da atividade antibacteriana do extrato etanólico das folhas de Jatropha mollissima, coletada em Tauá-CE, frente as cepas bacterianas testadas, foi constatado somente a ação antibacteriana do extrato na concentração de $250 \mathrm{mg} / \mathrm{mL}$, pois o mesmo apresentou 7,03 $\mathrm{mm}$ de halo de inibição (HI) do crescimento da bactéria Gram-positiva Enterococcus faecalis ATCC 29212, significantemente menor $(p<0,05)$ que o halo de inibição apresentado pelo controle positivo estreptomicina (HI igual a 12,30 mm), Tabela 1. Esse resultado é considerado importante, pois assim como assinalam de Oliveira et al. (2011), extratos vegetais que apresentam halos de inibição do crescimento microbiano entre 7 e 13 mm são considerados extratos promissores com moderada atividade antibacteriana.

Enterococcus faecalis é uma bactéria Grampositiva, comensal do sistema digestivo humano e de outros mamíferos, amplamente encontrada no ambiente, especialmente em ambientes hospitalares, que pode causar infecção urinária e meningite a pacientes imunocomprometidos (Muruzábal-Lecumberri et al., 2015). Assim, os resultados apresentados neste trabalho são considerados promissores, pois foi confirmada a ação antibacteriana moderada do extrato etanólico das folhas de J. mollissima contra esta cepa.

Este resultado corrobora com os relatos descritos por Mariz et al. (2010) e Sabandar et al. (2013), os quais afirmam que extratos orgânicos de espécimes do gênero Jatropha são considerados antibacterianos. Desta forma, no presente estudo utilizou-se esta ação antibacteriana do extrato etanólico das folhas de J. mollissima para justificar a investigação das principais classes de metabólitos secundários, pois assim como assinala Oliveira et al. (2012), a investigação da constituição química dos extratos vegetais é fundamental para a associação entre os compostos bioativos presentes neles com as respectivas propriedades farmacológicas.

A análise fitoquímica preliminar do extrato etanólico das folhas de J. mollissima, coletada em Tauá-CE, revelou a presença de diversas classes de metabólitos especiais, a saber: cumarinas, taninos, flavonoides (flavanóis, flavanonas), alcaloides e esteroides (Tabela 2). Vale salientar que neste extrato não foi detectado a presença de triterpenóides.

Esse resultado corrobora com os relatos descritos por Mariz et al. (2010), os quais afirmam que em extratos aquosos e orgânicos de partes de uma espécie de Jatropha já foram detectados as presenças de taninos, cumarinas e alcaloides.

Dados na literatura reportam que plantas contendo a presença de cumarinas (Reschke et al., 2007), taninos (Mendes et al., 2011), flavonóis e flavanonas (De Pinho et al., 2012), esteroides e alcaloides (Bessa et al., 2013), bem como compostos fenólicos (Firmo et al. 2014), podem conferir atividade antimicrobiana a um extrato, o que nos leva à justificativa desta ação antibacteriana do extrato etanólico das folhas de J. mollisima contra E. faecalis ATCC 29212, pela presença de classes

TABELA 1. Resultado da atividade antibacteriana do extrato etanólico das folhas de J. mollissima, coletada em Tauá-CE.

\begin{tabular}{|c|c|c|c|c|c|c|}
\hline \multirow[b]{2}{*}{ Amostra } & \multirow[b]{2}{*}{ Concentrações } & \multicolumn{5}{|c|}{ Cepas Bacterianas Padrões } \\
\hline & & Ec & $\mathrm{Pa}$ & $\mathrm{Ha}$ & $E f$ & $K p$ \\
\hline Etanol $^{*}$ & Comercial 96\% & $0,00 \pm 0,00^{a A}$ & $0,00 \pm 0,00^{\mathrm{aA}}$ & $0,00 \pm 0,00^{\mathrm{aA}}$ & $0,00 \pm 0,00^{\mathrm{aA}}$ & $0,00 \pm 0,00^{\mathrm{aA}}$ \\
\hline Clorafen.* & $4 \mathrm{mg} / \mathrm{mL}$ & $27,90 \pm 0,32^{\mathrm{aв}}$ & $19,40 \pm 0,60^{\text {вв }}$ & $28,70 \pm 1,50^{\text {ав }}$ & $26,50 \pm 1,10^{\mathrm{aв}}$ & $31,50 \pm 0,46^{\mathrm{cB}}$ \\
\hline Estrep.* & $1 \mathrm{mg} / \mathrm{mL}$ & $16,50 \pm 1,18 \mathrm{ac}$ & $15,90 \pm 1,01 \mathrm{ac}$ & $14,20 \pm 0,72^{\mathrm{ac}}$ & $12,30 \pm 1,31 \mathrm{bc}$ & $19,67 \pm 1,50$ cc \\
\hline E. Folhas & $250 \mathrm{mg} / \mathrm{mL}$ & $0,00 \pm 0,0^{\circ} \mathrm{A}$ & $0,00 \pm 0,00^{\mathrm{aA}}$ & $0,00 \pm 0,00^{\mathrm{aA}}$ & $7,03 \pm 0,15^{\mathrm{bD}}$ & $0,00 \pm 0,00^{\mathrm{aA}}$ \\
\hline E. Folhas & $25 \mathrm{mg} / \mathrm{mL}$ & $0,00 \pm 0,00^{\mathrm{aA}}$ & $0,00 \pm 0,00^{\mathrm{aA}}$ & $0,00 \pm 0,00^{a A}$ & $0,00 \pm 0,00^{\mathrm{aA}}$ & $0,00 \pm 0,00^{a A}$ \\
\hline
\end{tabular}

*Controles positivos e negativo; Clorafen - Clorafenicol; Estrep- Estreptomicina; E-extrato; Ec-Escherichia coli ATCC 25922; Pa-Pseudomonas aeruginosa ATCC 27853; Ha-Hafnia alvei ATCC 51873; Ef-Enterococcus faecalis ATCC 29212; Kp-Klebsiella pneumoniae ATCC 13883; Sem atividade antibacteriana $(\mathrm{HI}=0 \mathrm{~mm})$; Pouca atividade antibacteriana $(0 \mathrm{~mm}<\mathrm{HI}<7 \mathrm{~mm})$; Moderada atividade antibacteriana $(7 \mathrm{~mm}$ $\leq \mathrm{HI} \leq 13 \mathrm{~mm}$ ); Elevada atividade antibacteriana $(\mathrm{HI}>13 \mathrm{~mm})$; Letras pequenas iguais indicam que não houve diferença significativa entre as médias nas linhas ( $p<0.05)$; Letras grandes iguais indicam que não houve diferença significativa entre as médias nas colunas $(p<0,05)$ 
TABELA 2. Análise fitoquímica preliminar do extrato etanólico das folhas de J. mollissima, coletada em Tauá-CE.

\begin{tabular}{cccccccccc}
\hline Extrato etanólico & \multicolumn{8}{c}{ Classes de Metabólitos Es peciais (CME) } \\
\hline & CME1 & CME2 & CME3 & CME4 & CME5 & CME6 & CME7 & CME8 \\
\cline { 2 - 8 } Folhas & + & + & + & + & + & + & + & -
\end{tabular}

CME1-cumarinas; CME2-fenóis; CME3-taninos; CME4-flavonóis; CME5-flavanonas; CME6-alcalóides; CME7-esteróides; CME8triterpenóides; $(+)$ - presente; (-) - ausente.

de metabólitos secundários apresentadas.

Matias et al. (2010) afirmaram que as propriedades antimicrobianas dos taninos parecem estar associadas com a hidrólise de uma ligação éster do ácido gálico, que serve como um mecanismo de defesa natural contra as infecções microbianas. Os autores afirmam também que os flavonoides (flavonóis e flavanonas) são sintetizados por plantas em resposta à infecção microbiana e são eficazes contra uma ampla variedade de microrganismos e que sua atividade antimicrobiana se dá provavelmente devido à sua capacidade de formar complexos com proteínas solúveis que se ligam à parede celular bacteriana, bem como alguns flavonoides lipofílicos podem também causar ruptura da membrana plasmática de microrganismos.

Assim como assinalam Bessa et al. (2013), os testes fitoquímicos realizados com extratos vegetais revelam a presença de vários grupos de metabólitos secundários que podem contribuir para a identificação de marcadores químicos para as espécies em estudo, sendo estes indispensáveis para os testes de qualidade e integridade de fitoterápicos, conforme preconiza a Resolução RDC n. 14/2010 - da Agencia Nacional de Vigilância Sanitária-ANVISA, do Ministério da Saúde. Estas substâncias marcadoras características tornam a matéria prima mais conhecida, sendo fator importante para padronização de fitoterápicos, especialmente mediante a grande variabilidade química das plantas medicinais. Nesta perspectiva se tem melhorias no controle farmacognóstico das espécies, evitando a adulteração e uso inadequado das plantas medicinais.

Baseando-se no exposto, bem como no fato de que extratos vegetais bioativos podem ser uma alternativa aos compostos antibióticos (De Oliveira et al., 2011), os resultados aqui apresentados confirmam a importância farmacológica do extrato etanólico das folhas de J. mollissima, coletada em Tauá-CE, sendo relevante no âmbito da Caatinga, bioma prioritário para conservação da biodiversidade, visto a possibilidade de futuramente verificar atividade antimicrobiana mais expressiva desse extrato vegetal, direcionadas pela presença de grupos de metabólitos secundários de interesse.

\section{CONCLUSÃO}

Os resultados obtidos neste estudo confirmam que o extrato etanólico das folhas de J. mollissima, coleta em Tauá-CE, apresentou significante atividade antimicrobiana contra a cepa Enterococcus faecalis ATCC 29212, provavelmente devido as presenças de vários metabólitos secundários tais como cumarinas, fenóis, taninos, flavonoides (flavonóis e flavanonas), alcaloides e esteroides, ambas as classes reportadas como antimicrobianos. Vale salientar que o extrato se mostrou tóxico contra Artemia salina e não deve ser empregado como fitoterápico, porém, deve ser utilizado como fonte de compostos biotativos usados na produção de fármacos contra infecções causadas por bactérias Gram-positivas. No entanto, as informações direcionam estudos futuros para o isolamento e identificação dos compostos bioativos, monitorados sob a ação antibacteriana mais expressiva.

\section{AGRADECIMENTOS}

A todos os colaboradores do Grupo de Pesquisa Biotecnologia em Recursos Naturais, da UECE-CECITEC-Tauá. A todos que fazem o Laboratório de Bioquímica Humana-UECE, bem como a UECE, FUNCAP e CNPq, pelo apoio e suporte financeiro.

\section{REFERÊNCIAS}

ANDRADE, F.D.; et al. Ação anti-helmíntica do extrato hidroalcóolico da raiz da Tarenaya spinosa (Jacq.) Raf. no controle de Haemonchus contortus em ovinos. Pesquisa Veterinária Brasileira, v.34, n. 10, p. 942946, 2014.

BESSA, N.G.F.; et al. Prospecção fitoquímica preliminar de plantas nativas do cerrado de uso popular medicinal pela comunidade rural do assentamento vale verde Tocantins. Revista Brasileira de Plantas Medicinais, v.15, n.4, p.692-707, 2013.

BOSE, U.; et al. Antinociceptive, cytotoxic and antibacterial activities of Cleome viscosa leaves. Revista Brasileira de Farmacognosia, v.21, n.1, p.165-169, 2011.

CARTAXO, S.L.; et al. Medicinal plants with bioprospecting potential used in semi-arid Northeastern Brazil. Journal of Ethnopharmacology, v.131, n.2, p.326-342, 2010.

DE OLIVEIRA, R.L.; et al. Bioprospecção da atividade antimicrobiana e antioxidante, in vitro, do extrato hidroalcoólico de Piptadenia pterosperma Benth. 
Revista Brasileira de Farmácia, v.92, n.4, p.362-366, 2011.

OLIVEIRA, K.A.M.; et al. Atividade antimicrobiana e quantificação de Flavonoides e Fenóis totais em diferentes extratos de Própolis. Semina: Ciências Biológicas e da Saúde, v.33, n.2, p.211-222, 2012.

DE PINHO, L.; et al. Atividade antimicrobiana de extratos hidroalcoolicos das folhas de alecrim-pimenta, aroeira, barbatimão, erva baleeira e do farelo da casca de pequi. Ciência Rural, v.42, n.2, p.326-331, 2012.

FIRMO, W.C.A.; et al. Estudo fitoquímico e avaliação da atividade antibacteriana de Lafoensia pacari (Lythraceae). Publicatio UEPG: Ciências Biológicas e da Saúde, v.20, n.1, p. 7-12, 2014.

MARIZ, S.R.; et al. Possibilidades terapêuticas e risco toxicológico de Jatropha gossypiifolia L.: uma revisão narrativa. Revista Brasileira de Plantas Medicinais, v.12, n.3, p.346-357, 2010.

MATIAS, E.F.F.; et al. Atividade antibacteriana In vitro de Croton campestris A., Ocimum gratissimum L. e Cordia verbenacea DC. Revista Brasileira de Biociências, v.8, n.3, p.294-298, 2010.

MENDES, L.P.M.; et al. Atividade antimicrobiana de extratos etanólicos de Peperomia pelúcida e Portulaca pilosa. Revista de Ciências Farmacêutica Básica e Aplicada, v.32, n,1, p.121-125, 2011.

MEYER, B.N.; et al. Brine shrimp: a convenient general bioassay for active plant constituents. Journal Medical Plants Research, v.45, p.31-34, 1982.

MURUZÁBAL-LECUMBERRI, I.; et al. Spread of na Enterococcus faecalis sequence type 6 (CC2) clone in patients undergoing selective decontamination of the digestive tract. Actha Pathologica, Microbiologica Et Imunologica Scandinavica, v.123, p.245-251, 2015.

PEREIRA, V.S.; et al. Estudo químico, toxicidade e atividade antibacteriana do óleo essencial de Ocimum gratissimum. Revista Interfaces, Ano 2. Vol. 2, Número Especial, p. 1-5, 2014.

RESCHKE, A.; et al. Atividade antibacteriana de Ficus benjamina L. (Moraceae). Revista Brasileira de Plantas Medicinais, v.9, n.2, p.67-70, 2007.

RIBEIRO, A.R.C.; et al. Estudo da atividade anti-helmíntica do extrato etanólico de Jatropha mollissima (Pohl) Baill. (Euphorbiaceae) sob Haemonchus contortus em ovinos no semiárido paraibano. Pesquisa Veterinária Brasileira, v.34, n.11, p.1051-1055, 2014.

SABANDAR, C.W.; et al. Medicinal property, phytochemistry and pharmacology of several Jatropha species (Euphorbiaceae): A review. Phytochemistry, v.85, p.7-29, 2013.

SIMÕES, R.C; de ALMEIDA, S.S.M.S. Estudo fitoquímico de Bauhinia forficata (Fabaceae). Biota Amazônia, v.5, n.1, p.27-31, 2015.

SOBRAL, I.S.; et al. Xantonas, triterpenos e atividade antibacteriana do extrato em diclorometano de Kielmeyera cuspidata Saddi, Clusiaceae. Revista Brasileira de Farmacognosia, v.19, n.3, p.686-689, 2009.

SOUSA, E. O.; et al. Phytochemical analysis and antioxidant activities of Lantana camara and Lantana montevidensis extracts. Industrial Crops and Products v.70, p.7-15, 2015.

SOUZA, W.M.A.; et al. Atividade in vitro do extrato hidroalcoólico de Lippia sidoides Cham sobre larvas de terceiro estágio de nematódeos gastrointestinais (Família Trichostrongylidae) de caprinos. Arquivos do Instituto Biológico, v.78, n.1, p.119-122, 2011.

TURNES, J. M.; et al. Avaliação da atividade antioxidante e alelopática do extrato etanólico e frações das cascas do caule de Zanthoxylum rhoifolium Lam., Rutaceae. Revista de Ciências Farmacêuticas Básica e Aplicada, v. 35, n. 3, p. 459-467, 2014. 